Brit. J. soc. Med. (1947), 1, 18-32.

\title{
A DOCUMENTARY STUDY OF JAUNDICE ASSOCIATED WITH SYPHILIS TREATMENT AND BLOOD TRANSFUSION
}

BY

\author{
SIDNEY C. TRUELOVE, M.A., M.D. \\ (Late Lt.-Col., R.A.M.C.) \\ AND \\ LANCELOT HOGBEN, F.R.S. \\ (Consultant in Army Medical Statistics)
}

(Received May 3, 1945)

\section{INTRODUCTION}

A formidable problem of wartime medicine has been widespread prevalence of infective hepatitis especially in the Mediterranean zone, where it was one of the three major sources of wastage among troops. Although there was no comparable epidemic in the United Kingdom its incidence among civilians and troops alike was almost certainly much higher than in the preceding decade. A concomitant phenomenon was the occurrence of jaundice with many similar features among Army patients treated for syphilis, among individuals inoculated with vaccines containing human serum and among casualties who received blood transfusions.

Indeed, an alarming incidence of jaundice among Army syphilitics was an outstanding medical enigma of the war. To be sure, its occurrence as a complication of arsenical treatment has been recognized since 1910, but never on a comparable scale. Reliable figures for the first two years of the war are not available; but such evidence as is available suggests that its incidence rose gradually (Beattie and Marshall, 1943). By the first half of 1943 approximately 1 in 2 of all soldiers under long-term arsenic therapy developed jaundice during the course of their treatment; and by mid 1943 there was evidence to suggest that this was largely the result of infection from contaminated syringes employed for intravenous injection and venipuncture (MacCallum, 1943; Salaman et al., 1944). Accordingly Army medical authorities promulgated instructions to all venereal disease treatment centres in U.K. to promote more careful sterilization of implements. Where possible syringes as well as needles were to be boiled between injections, but adaptors to prevent reflux of blood were issued as an interim measure, if shortage of syringes prevented full implementation of the policy. Meanwhile, individual treatment centres acting on their own initiative had already adopted precautionary measures.

At this time, but in a different context, the occurrence of jaundice had forced itself on the attention of the American Army Medical Service. In 1942, 28,000 cases of jaundice occurred among American troops inoculated with yellow fever vaccine containing pooled human serum as a component; but no further outbreak occurred since introduction of a new method of manufacture of the vaccine to 
exclude human serum. (Circular letter of the Surgeon-General, 1942.) The Ministry of Health (1943) has summarized findings in previous outbreaks of homologous serum jaundice and has drawn attention to the danger of blood transfusion. Beeson (1943), Steiner (1943), and Morgan and Williamson (1943) have also severally reported cases of jaundice occurring in patients who had been transfused one to four months previously. The widespread occurrence of infective hepatitis at this time and clinical similarities of the several forms of jaundice encouraged the belief that delayed jaundice associated with arsenotherapy, inoculation, and blood transfusion are all manifestations of the presence of the virus responsible for infective hepatitis itself. On the other hand, there were striking discrepancies. Thus clinical experience (Pickles, 1939) ascribes the limits of the incubation period of infective hepatitis between 21 and 40 days; but that of homologous serum jaundice is decidedly more protracted. McKinlay and Truelove (1946) have brought forward other evidence pointing to the conclusion that the putative icterogenic agent of so-called post-arsphenamine jaundice is not the virus of infective hepatitis.

The aim of this study is to examine the documentary resources of Army statistical medicine with a view to elucidating:

(i) whether special precautions against contamination of syringes used in V.D. clinics are justified by results; and hence whether the hypothesis which attributes jaundice during treatment for syphilis to a blood-borne icterogenic agent is valid;

(ii) how far liability to jaundice during treatment for syphilis also depends on:

(a) direct toxic action of arsenicals;

(b) concomitant presence of treponema pallidum;

(iii) whether the virus of infective hepatitis is also responsible for jaundice associated with syphilis treatment and/or delayed jaundice following blood transfusion.

The expression delayed jaundice used in (iii) above signifies that cases dealt with in this communication are only such as occur after a lapse of time sufficient to exclude those due to antigen-serum incompatibilities.

\section{Documentary Materials}

Army medical records furnish unique opportunities for large-scale enquiries involving prolonged follow-up of patients. A central index at the War Office retains case records of all Army patients filed in order of personal number. Though a soldier may receive treatment in several hospitals all his case records are together and collectively afford a complete accessible dossier of his medical history in the Army, in so far as it involves hospital treatment. A second file of punched cards containing certain data required for routine vital statistics including personal number, diagnosis, and date of admission is also available for mechanical extraction of a nominal roll of cases of any disease over a given period. By recourse to such a roll (based on the personal numbers of the patients), it is possible to refer to the 
complete record in the central index. For syphilis patients the War Office holds a supplementary file recording with relevant details all visits for out-patient treatment or surveillance. Cases of blood transfusion are not coded as such for the preparation of punched cards; but nominal rolls of battle casualties, of which a considerable proportion received such treatment, were available for this enquiry. The labour involved in sorting these cases was partly short-circuited through the good offices of Colonel W. d'A. Maycock, Commandant, Army Blood Supply Depot, who supplied a list of approximately 1,500 military patients with transfusion treatment in F.T.U.s during the Normandy campaign from June to November 1944. Details of the amount and nature of the transfusion (i.e. whole blood or plasma) were included. All cases were first checked through Record Offices to classify them as: (a) dead; $(b)$ effectives; $(c)$ discharged, with appropriate date. Case records of all men who were effective at the time of the inquiry (September 1945 onwards) and of discharged men were then examined in detail. Details of transfusions were checked and additional transfusions after evacuation to U.K. were noted. Cases without complete medical documents from admission to a medical unit until final discharge from hospital or convalescent depot were rejected. The case records of three classes of patient satisfactory for follow-up over a minimum period of six months after transfusion were examined for evidence of jaundice: (a) effectives; (b) discharged from the Army after more than 6 months' stay in hospital; (c) discharged from the Army after less than 6 months in hospital but more than 6 months after transfusion. The size of this residual sample was 462 .

For the study of jaundice associated with treatment of syphilis the sample was made up of: (a) cases in the United Kingdom during 1943 and 1944; $(b)$ a smaller group of overseas cases treated with penicillin in the latter part of 1944 alone. It will be convenient to present the results of the enquiry separately with respect to the three main treatments in use, viz. long-term arsenic (L.T.A.), short-term arsenic (S.T.A.), and penicillin (PEN). Cases treated with the first of these make up a large bulk of the total sample. Consequently, they supp.y the greater part of the evidence relevant to the issues investigated.

In any investigation of the statistics of disease it is necessary to examine the role of variables known to distort impressions gained from crude figures. An outstanding one is age. The incidence of so-called post-arsphenamine jaundice is much the same in all age-groups of the Army population of syphilitics. From the U.K. sample of this inquiry we get the following rates, none of which differs significantly from the overall value of $34 \cdot 4 \% \pm 1 \cdot 1$.

$\begin{array}{lc}\text { Age } & \% \text { incidence } \\ 18-20 & 35 \cdot 2 \pm 4 \cdot 0 \\ 21-25 & 36 \cdot 1 \pm 2 \cdot 0 \\ 26-30 & 33 \cdot 5 \pm 2 \cdot 0 \\ 31-35 & 32 \cdot 6 \pm 2 \cdot 5 \\ 36-40 & 37 \cdot 9 \pm 3 \cdot 5 \\ \text { Over } 40 & 29 \cdot 9 \pm 4 \cdot 1\end{array}$


By contrast, infective hepatitis, like other communicable diseases which confer immunity, is relatively more common in the younger age groups. As elsewhere pointed out independently by McKinlay and Truelove (ibid.) and Hogben and Johnstone (1946), this contrast offers a powerful objection to the view that the virus of infective hepatitis is responsible for jaundice during treatment of syphilis.

3. Declining Incidence of Jaundice associated with Syphilis Treatment

The following figures based on 1,955 L.T.A. cases show that the percentage incidence of jaundice among L.T.A. cases underwent a spectacular decline foreshadowed in the second half of 1943 ; i.e. after introduction of new instructions (June 1943) with respect to sterilization of syringes.

$\begin{array}{lr}\text { January-June 1943 } & 45 \cdot 1 \pm 1 \cdot 9 \\ \text { July-December 1943 } & 39 \cdot 8 \pm 1 \cdot 9 \\ \text { January-June 1944 } & 20 \cdot 6 \pm 1 \cdot 8 \\ \text { July-December 1944 } & 5 \cdot 4 \pm 2 \cdot 0 \\ \text { Whole period 1943-44 } & 34 \cdot 4 \pm 1 \cdot 1\end{array}$

Since the view which prompted the new regulations was already gaining ground by the middle of 1943, it is instructive to break down the L.T.A. sample by the individual centres at which patients started treatment (Tables I and II). The distribution of cases with respect to time of onset in Table III shows that about one-third of jaundice cases occurred before a patient could have started a second course of treatment; and since the data point to a long period of incubation, the infective hypothesis implies that the overwhelming majority of cases became infected before starting a second course in a centre other than the one at which they first received treatment. Table I shows that the level of incidence was universally though not uniformly high in the first half of 1943; and decline was conspicuously unequal thereafter.

In view of evidence with respect to the mean incubation period set out later, we may consider cases of jaundice occurring less than 150 days after beginning of treatment as due to infection in the first treatment centre. Table II, which refers only to such cases, emphasizes the two conclusions stated above. Comparable figures for S.T.A. cases are too few to be worthy of discussion in this context; but scrutiny of the penicillin cases discloses a noteworthy feature. These included a U.K. group of 290 and an overseas sample of 124 . The incidence of jaundice among them (August 1944-February 1945) was as follows:
U.K.
$2 \cdot 0 \pm 0 \cdot 9$
Overseas
$20 \cdot 2 \pm 3 \cdot 6$

This striking difference with respect to the use of one and the same drug is not entirely unequivocal, since it may conceivably be at least in part attributable to the general health of the patients. None the less, it is entirely consistent with the view that jaundice in syphilitics under treatment can be propagated by insufficient care with respect to sterilization of instruments.

It seems clear that a fairly high proportion of the syphilitic population was 

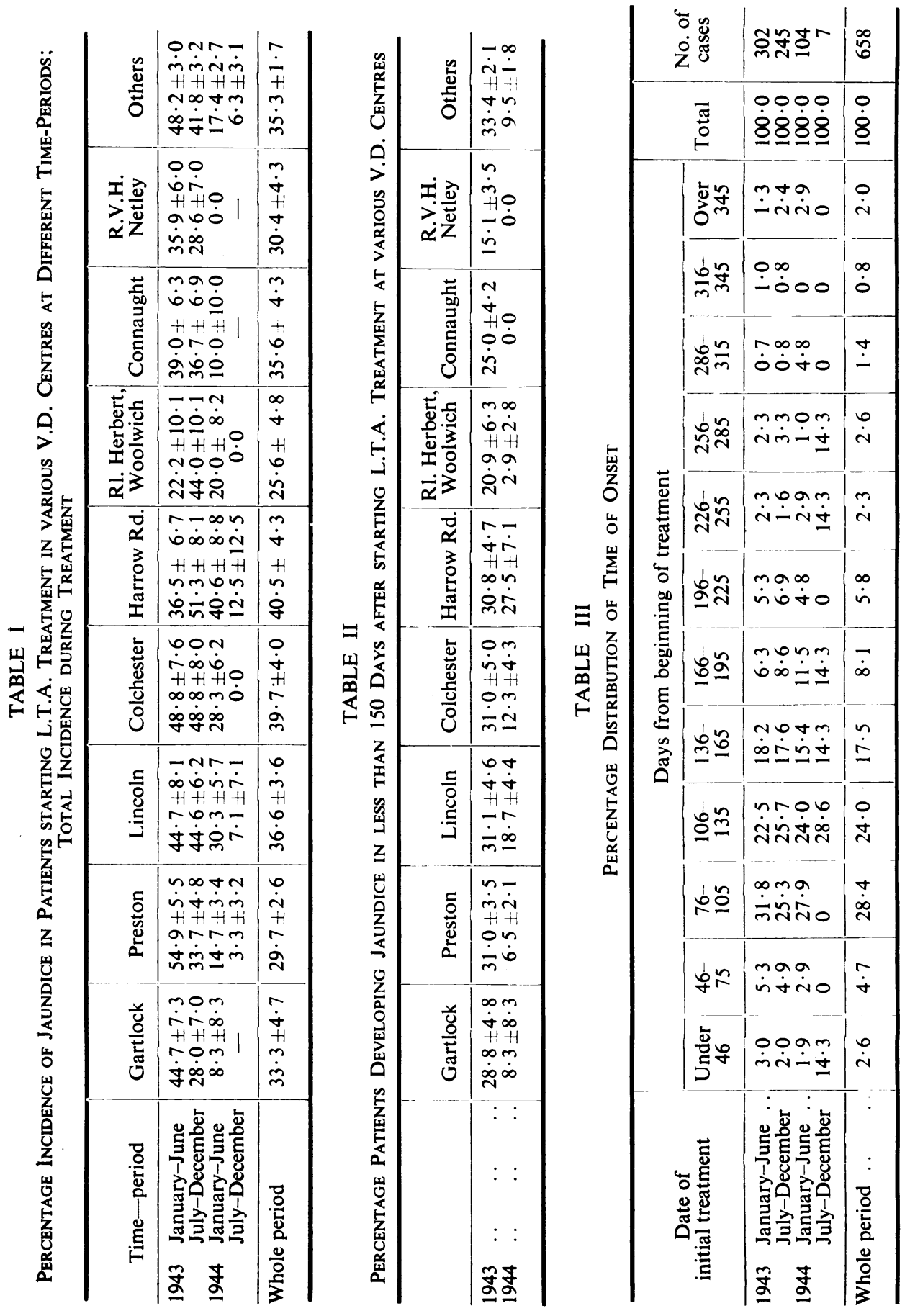
infected with the icterogenic agent during the peak period of incidence at the beginning of 1943. In such circumstances the probability of infection at an early stage of treatment was high, and this sufficiently explains the high concentration of cases whose time of onset was in the zone between 75 and 135 days from the beginning of the first course. By the same token we might expect to find a much greater spread towards the upper limit of the time of onset as the gross incidence of jaundice declined with concomitant proportionate reduction of carriers. That this is not so calls for explanation. Indeed, the figures in Table III suggest that susceptibility to the infective agent is maximal at the beginning of treatment, being thus dependent on the syphilitic process.

The high incidence of jaundice among syphilitics at the beginning of 1943 is in striking contrast to the known incidence of jaundice among patients simultaneously treated with pooled homologous sera. Evidence from this source indicates that the proportion of persons who react by delayed jaundice to transfusion with blood obtained from large pool of donors is not high, being about $5 \%$. This is not what the high figures for jaundiced syphilitics at the beginning of 1943 might lead us to suppose, if we accept the hypothesis that such jaundice is in fact determined by an agent spread by syringes contaminated with blood of infected individuals. Among others, two explanations for the anomaly suggest themselves:

(a) that the procedure of Army venereal disease clinics before 1943 constituted a selective machinery for the build up of a population isolate with an inordinately high proportion of infected donors and/or a stock of instruments more or less permanently contaminated with the icteric agent;

(b) that circumstances peculiar to the treatment of syphilis and/or to the syphilitic process itself favour high susceptibility to such blood-borne infective agents as may evoke icterus in appropriate circumstances.

The second issue is the theme of the section which follows.

\section{Significance of Arsenicals and of the Syphilitic Process}

The hypothesis that an infective agent is a necessary condition for development of jaundice does not necessarily imply that it is also a sufficient one. How far the nature and quantity of the drug and how far the syphilitic process are respectively among contributory circumstances propitious to icteric manifestations are issues which we can disentangle only by a simultaneous breakdown of our data with respect to both. In comparing results of different therapies we shall therefore split our cases with respect to the stage of disease when treatment began. Needless to say, valid interpretation of data bearing on either of the issues involved presupposes due consideration of the distribution of cases by date of starting treatment; but it would be unduly prolix to present all the ensuing data separately for comparable periods. It must suffice to say that such data with respect to long-term arsenotherapy throughout the whole period, as appear in Table IV, point to conclusions consistent with data classified separately for three-monthly periods. Similar remarks apply mutatis mutandis to other comparisons below, unless there is a 
statement to the contrary. Table IV exhibits no statistically significant differences with respect to the incidence of jaundice among patients respectively receiving long-term neoarsphenamine and mapharside at the same stage of the disease when treatment started. Rates for patients receiving short-term arsenotherapy and penicillin are not comparable, since these treatments came into use only at the end of the period to which Table IV refers.

\section{TABLE IV}

Percentage Incidence of Jaundice in Relation to Nature of Arsenical DRUg Employed for First Course and Stage of Syphilis at Which TREATMENT BEGAN

\begin{tabular}{l|c|c}
\hline Stage of disease & $\begin{array}{c}\text { N.A.B. } \\
(1,010 \text { cases })\end{array}$ & $\begin{array}{c}\text { Mapharside } \\
(209 \text { cases })\end{array}$ \\
\hline $\begin{array}{l}\text { Primary } \\
\text { Unspecified }\end{array}$ & $\begin{array}{l}44 \cdot 9 \pm 6 \cdot 0 \\
\text { Primary }\end{array}$ & $35 \cdot 7 \pm 13 \cdot 3$ \\
$\begin{array}{l}\text { Sero-negative } \\
\text { Primary }\end{array}$ & $35 \cdot 4 \pm 2 \cdot 9$ & $34 \cdot 7 \pm 6 \cdot 8$ \\
$\begin{array}{l}\text { Sero-positive } \\
\text { Secondary }\end{array}$ & $39 \cdot 6 \pm 2 \cdot 5$ & $44 \cdot 7 \pm 5 \cdot 4$ \\
\hline
\end{tabular}

During the period under review there was a striking contrast between the liability of syphilis patients to jaundice and to indisputably toxic effects of arsenicals per se. The following figures based on the L.T.A. sample of this enquiry-show that rates for arsenical dermatitis, by far the most common complication of arsenotherapy other than hepatitis, remained constant while the incidence of jaundice underwent a spectacular decline.

$\begin{array}{lrc} & \% \text { Jaundice } & \% \text { Dermatitis } \\ \text { January-June 1943 } & 45 \cdot 1 \pm 1 \cdot 9 & 6 \cdot 6 \pm 3 \cdot 0 \\ \text { July-December } 1943 & 39 \cdot 8 \pm 1 \cdot 9 & 6 \cdot 2 \pm 3 \cdot 0 \\ \text { January-June 1944 } & 20 \cdot 6 \pm 1 \cdot 8 & 7 \cdot 5 \pm 3 \cdot 6 \\ \text { July-December 1944 } & 5 \cdot 4 \pm 2 \cdot 0 & 8 \cdot 5 \pm 7 \cdot 7\end{array}$

The data set forth above and rates for penicillin treatment cited earlier provide no grounds for believing that one or other form of arsenic treatment is more or less

TABLE V

Percentage Incidence of Jaundice related to Stage of Syphilis at which Treatment Began

\begin{tabular}{|c|c|c|c|c|c|c|}
\hline Time-period & $\begin{array}{l}\text { Primary } \\
\text { unspecified }\end{array}$ & $\begin{array}{c}\text { Primary } \\
\text { sero-negative }\end{array}$ & $\begin{array}{c}\text { Primary } \\
\text { sero-positive }\end{array}$ & Secondary & $\begin{array}{c}\text { No clinical } \\
\text { sero-positive }\end{array}$ & All stages \\
\hline $\begin{array}{l}\text { 1943: } \\
\text { January-June } \\
\text { July-December } \\
\text { 1944: }\end{array}$ & $\begin{array}{l}41 \cdot 1 \pm 6 \cdot 6 \\
50 \cdot 0 \pm 6 \cdot 6\end{array}$ & $\begin{array}{l}44 \cdot 1 \pm 3 \cdot 8 \\
40 \cdot 6 \pm 3 \cdot 8\end{array}$ & $\begin{array}{l}52 \cdot 0 \pm 3 \cdot 1 \\
40 \cdot 7 \pm 3: 1\end{array}$ & $\begin{array}{l}36 \cdot 8 \pm 3 \cdot 5 \\
33 \cdot 1 \pm 4 \cdot 0\end{array}$ & $\begin{array}{l}57 \cdot 1 \pm 11 \cdot 6 \\
28 \cdot 6 \pm 12 \cdot 5\end{array}$ & $\begin{array}{l}45 \cdot 1 \pm 1 \cdot 9 \\
39 \cdot 6 \pm 1 \cdot 9\end{array}$ \\
\hline $\begin{array}{l}\text { January-June } \\
\text { July-December }\end{array}$ & $\begin{array}{c}22 \cdot 0 \pm 5 \cdot 8 \\
0 \cdot 0\end{array}$ & $\begin{array}{r}20 \cdot 8 \pm 3 \cdot 6 \\
5 \cdot 9 \pm 4 \cdot 0\end{array}$ & $\begin{array}{r}24 \cdot 0 \pm 3 \cdot 5 \\
9 \cdot 8 \pm 4 \cdot 1\end{array}$ & $\begin{array}{c}15 \cdot 3 \pm 2 \cdot 9 \\
0 \cdot 0\end{array}$ & $\mid \begin{array}{c}33 \cdot 3 \pm 11 \cdot 4 \\
0 \cdot 0\end{array}$ & $\begin{array}{r}20 \cdot 6 \pm 1 \cdot 8 \\
5 \cdot 5 \pm 2 \cdot 0 \\
\end{array}$ \\
\hline Whole period & $37 \cdot 7 \pm 3 \cdot 7$ & $34 \cdot 1 \pm 2 \cdot 1$ & $38 \cdot 9 \pm 1 \cdot 8$ & $27 \cdot 0 \pm 1 \cdot 9$ & $37 \cdot 3 \pm 6 \cdot 3$ & $34 \cdot 3 \pm 1 \cdot 1$ \\
\hline
\end{tabular}


propitious to overt jaundice in the absence of adequate precautions against syringe contamination, nor any reason to suppose that arsenotherapy is more risky than penicillin if precautions are in fact adequate.

We have now to ask whether the syphilitic process as such plays a significant contributory role. In this context the syphilitic process signifies any relevant conditions arising from the disease itself. Table $\mathrm{V}$ brings out a striking difference which suggests an affirmative answer to the question stated last. The contrast is more explicit if we condense information therein with respect to jaundice rates as follows:

$\begin{array}{lccc} & \text { Primary stage } & \text { Secondary stage } & \text { All stages } \\ \text { January-June 1943 } & 48 \cdot 0 \pm 2 \cdot 3 & 36 \cdot 8 \pm 3 \cdot 5 & 45 \cdot 1 \pm 1 \cdot 9 \\ \text { July-December 1943 } & 41 \cdot 8 \pm 2 \cdot 3 & 33 \cdot 1 \pm 4 \cdot 0 & 39 \cdot 6 \pm 1 \cdot 9 \\ \text { January-July 1944 } & 19 \cdot 4 \pm 1 \cdot 9 & 12 \cdot 6 \pm 2 \cdot 4 & 17 \cdot 5 \pm 1 \cdot 5\end{array}$

We have here definite evidence for the view that the syphilitic process does play a significant contributory role in the phenomenon under discussion. For reasons already stated, this receives some support from the trend of rates shown in Table III. It is also sustained by the appreciable incidence of jaundice among syphilitic patients treated with penicillin, a drug which is not of itself an agency contributory to jaundice. Among 296 cases of gonorrhoea treated with intramuscular penicillin in U.K. clinics from July 1944 to September 1945 no single individual had developed jaundice by the end of 1945 . From another enquiry undertaken in the Directorate of Medical Statistics at the War Office by Dr. Hunt, we have other evidence for the view that penicillin does not increase liability to jaundice. Examination of cases of jaundice among battle casualties treated with or without systemic penicillin discloses the following rates:

With transfusion and systemic penicillin (B.L.A.) $\quad$.. $\quad 4 \cdot 3 \quad \pm 0 \cdot 8$

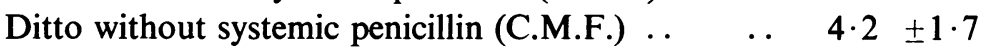

Without transfusion with systemic penicillin (B.L.A.) .. $\quad 0 \cdot 35 \pm 0 \cdot 1$

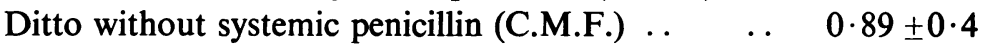

5. Delayed Jaundice associated with Blood Transfusion

Although penicillin, per se, exerts no influence on liability to jaundice, evidence set forth above shows that blood transfusion is commonly associated with increased liability. Before proceeding to the exposition of other data bearing more directly on the nature of the agent or agents respectively responsible for jaundice associated with treatment of syphilis and delayed jaundice following blood transfusion, it is appropriate to draw attention to an important difference between rates for delayed jaundice among two classes of casualties which received transfusion, viz. those who received whole blood only and those who received plasma. The following figures show that plasma as used for these cases is more icterogenic than whole blood.

\begin{tabular}{lcc|c} 
& No. of $\%$ developing & \\
patients & jaundice & Difference \\
Whole blood only & 248 & $0 \cdot 81 \pm 0 \cdot 32$ & $4 \cdot 33 \pm 1 \cdot 61$ \\
Plasma alone or with blood & 214 & $5 \cdot 14 \pm 2 \cdot 28$ &
\end{tabular}


A sufficient explanation of this difference is that:

(a) one bottle of whole blood comes from a single donor;

(b) one bottle of plasma comes from a pool to which many donors contribute.

Whereas a bottle of whole blood can carry an icterogenic agent from only one donor, a bottle of pooled plasma may indeed contain an icterogenic agent from any one of about 500 donors.

\section{The Incubation Period of the Several Types of Jaundice}

The table on p. 28 showing concomitant incidence of such other communicable diseases as occurred in a highly heterogeneous syphilitic population with a high

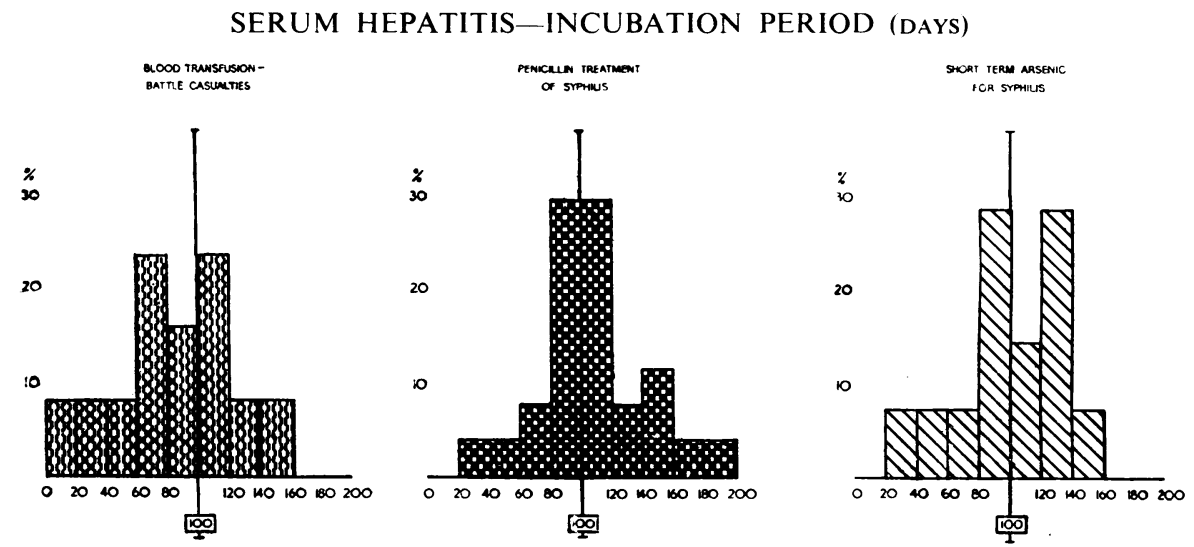

incidence of hepatitis shows that the putative infective agent of so-called postarsphenamine jaundice either stays longer in the blood stream or is vastly more resistant to sterilization procedures than the agent of any common communicable disease. If it is infective hepatitis, the virus of infective hepatitis must itself be very different in one or both ways from other viruses; but it is more probable that the jaundice in syphilis is evoked by an infective agent which is not the virus of infective hepatitis. One reason for believing so, and one sufficiently striking of itself, depends on its age distribution already mentioned on p. 20. The figures there shown refer to L.T.A. and the overseas penicillin sample is confirmatory in so far as rates for the age groups up to and over 25 are respectively $20 \cdot 0 \pm 6 \cdot 4$ and $19 \cdot 5 \pm 4 \cdot 4$. For reasons set forth by Hogben and Johnstone (1946) this suggests that the putative infective agent of post-arsphenamine jaundice does not evoke appreciable immunity to subsequent infection, as does the virus of infective hepatitis. It is therefore instructive to seek further information concerning the prophylactic effect of a previous attack of infective hepatitis. Our records provided only 10 cases of syphilitics with a previous history of the disease. Of these, 2 had jaundice during treatment in V.D. clinic. The incidence $20 \cdot 0 \pm 13 \cdot 3$ does not significantly differ from the overall figure $34 \cdot 5 \pm 1 \cdot 1$ for the same period. Of itself this signifies little, but is consistent with evidence of a field enquiry undertaken by McKinlay and Truelove (ibid.) in Italy where infective hepatitis was more prevalent. Their 
corresponding figures for 35 and 837 cases respectively with and without previous history of infective hepatitis were $34 \cdot 3 \pm 8 \cdot 1$ and $36 \cdot 3 \pm 1 \cdot 7$.

TABLE VI

Time of Onset of Jaundice in Relation to Stage of Disease at which Treatment Began (L.T.A. Serirs)

\begin{tabular}{|c|c|c|c|c|c|c|c|c|c|c|c|c|c|c|}
\hline \multirow{2}{*}{ Stage of Disease } & \multicolumn{12}{|c|}{ Days after beginning of treatment } & \multirow{2}{*}{ Total } & \multirow{2}{*}{$\begin{array}{l}\text { No. of } \\
\text { cases }\end{array}$} \\
\hline & $\begin{array}{c}\text { Under } \\
46\end{array}$ & $\begin{array}{r}46- \\
75\end{array}$ & $\begin{array}{l}76- \\
105\end{array}$ & $\begin{array}{l}106- \\
135\end{array}$ & $\begin{array}{l}136- \\
165\end{array}$ & $\begin{array}{l}166 \\
195\end{array}$ & $\begin{array}{c}-196- \\
225\end{array}$ & $\begin{array}{l}226- \\
255\end{array}$ & $\begin{array}{l}256- \\
285\end{array}$ & $\begin{array}{c}286- \\
315\end{array}$ & $\begin{array}{l}316- \\
345\end{array}$ & $\begin{array}{c}\text { Over } \\
345\end{array}$ & & \\
\hline 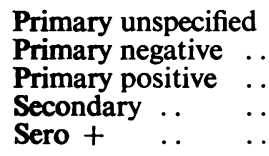 & $\begin{array}{l}1 \cdot 6 \\
1 \cdot 8 \\
2 \cdot 2 \\
4 \cdot 1 \\
5 \cdot 3\end{array}$ & $\begin{array}{l}6 \cdot 5 \\
6 \cdot 7 \\
3 \cdot 0 \\
4 \cdot 9 \\
5 \cdot 3\end{array}$ & $\begin{array}{l}27 \cdot 4 \\
30 \cdot 0 \\
26 \cdot 9 \\
28 \cdot 7 \\
36 \cdot 8\end{array}$ & $\begin{array}{l}29 \cdot 0 \\
24 \cdot 5 \\
21 \cdot 3 \\
27 \cdot 0 \\
18 \cdot 4\end{array}$ & $\begin{array}{l}11 \cdot 3 \\
17 \cdot 2 \\
20 \cdot 5 \\
14 \cdot 8 \\
15 \cdot 8\end{array}$ & $\begin{array}{l}8 \cdot 1 \\
6 \cdot 1 \\
9 \cdot 3 \\
8 \cdot 2 \\
7 \cdot 9\end{array}$ & $\begin{array}{l}3 \cdot 2 \\
4 \cdot 9 \\
6 \cdot 0 \\
9 \cdot 0 \\
2 \cdot 6\end{array}$ & $\begin{array}{l}1 \cdot 6 \\
3 \cdot 1 \\
2 \cdot 2 \\
2 \cdot 5 \\
-\end{array}$ & $\begin{array}{l}4 \cdot 8 \\
2 \cdot 5 \\
3 \cdot 4 \\
-\end{array}$ & $\begin{array}{l}\overline{1 \cdot 2} \\
2 \cdot 2 \\
- \\
2 \cdot 6\end{array}$ & $\begin{array}{l}-1 \cdot 2 \\
0 \cdot 7 \\
0 \cdot 8 \\
-\end{array}$ & $\begin{array}{l}6 \cdot 5 \\
0 \cdot 6 \\
2 \cdot 2 \\
0 \cdot 0 \\
5 \cdot 3\end{array}$ & $\begin{array}{l}100 \cdot 0 \\
100 \cdot 0 \\
100 \cdot 0 \\
100 \cdot 0 \\
100 \cdot 0\end{array}$ & $\begin{array}{r}62 \\
163 \\
268 \\
122 \\
38\end{array}$ \\
\hline
\end{tabular}

TABLE VII

Relation of Age to the time of ONSET of JAundice

\begin{tabular}{|c|c|c|c|c|c|c|c|c|c|c|c|c|c|c|c|}
\hline & \multirow{2}{*}{ Age } & \multicolumn{12}{|c|}{ Days after starting treatment } & \multirow{2}{*}{ Total } & \multirow{2}{*}{$\begin{array}{l}\text { No. of } \\
\text { cases }\end{array}$} \\
\hline & & $\begin{array}{c}\text { Under } \\
46\end{array}$ & $\begin{array}{l}46- \\
75\end{array}$ & $\begin{array}{l}76- \\
105\end{array}$ & $\begin{array}{l}106- \\
135\end{array}$ & $\begin{array}{l}136- \\
165\end{array}$ & $\begin{array}{c}166- \\
195\end{array}$ & $\begin{array}{l}196- \\
225\end{array}$ & $\begin{array}{c}226- \\
255\end{array}$ & $\begin{array}{l}256- \\
285\end{array}$ & $\begin{array}{c}286- \\
315\end{array}$ & $\begin{array}{r}316- \\
345\end{array}$ & $\begin{array}{l}\text { Over } \\
345\end{array}$ & & \\
\hline $\begin{array}{c}18-25 \\
26-30 \\
31-35 \\
36+\end{array}$ & $\begin{array}{l}\ldots \\
\cdots \\
\ldots\end{array}$ & $\begin{array}{l}2 \cdot 3 \\
2 \cdot 2 \\
3 \cdot 4 \\
2 \cdot 8\end{array}$ & $\begin{array}{l}5 \cdot 5 \\
3 \cdot 9 \\
3 \cdot 4 \\
5 \cdot 6\end{array}$ & $\begin{array}{l}29 \cdot 7 \\
26 \cdot 3 \\
28 \cdot 4 \\
29 \cdot 0\end{array}$ & $\begin{array}{l}25 \cdot 8 \\
26 \cdot 8 \\
24 \cdot 1 \\
15 \cdot 0\end{array}$ & $\begin{array}{l}16 \cdot 0 \\
18 \cdot 4 \\
19 \cdot 0 \\
17 \cdot 8\end{array}$ & $\begin{array}{l}7 \cdot 8 \\
7 \cdot 8 \\
9 \cdot 5 \\
7 \cdot 5\end{array}$ & $\begin{array}{l}5 \cdot 1 \\
3 \cdot 9 \\
6 \cdot 9 \\
9 \cdot 3\end{array}$ & $\begin{array}{l}2 \cdot 3 \\
2 \cdot 8 \\
0 \cdot 9 \\
2 \cdot 8\end{array}$ & $\begin{array}{l}2 \cdot 0 \\
2 \cdot 8 \\
0.9 \\
5 \cdot 6\end{array}$ & $\begin{array}{l}0.8 \\
2.8 \\
0.9 \\
0.9\end{array}$ & $\begin{array}{l}0.8 \\
0.6 \\
1.7 \\
-\end{array}$ & $\begin{array}{l}2 \cdot 0 \\
1 \cdot 7 \\
0.9 \\
3 \cdot 7\end{array}$ & $\begin{array}{l}100 \cdot 0 \\
100 \cdot 0 \\
100 \cdot 0 \\
100 \cdot 0\end{array}$ & $\begin{array}{l}256 \\
179 \\
116 \\
107\end{array}$ \\
\hline
\end{tabular}

An issue with respect to which our data provide a basis for more satisfactory comparison between the several types of jaundice is the period of incubation. Table III sets forth the case distribution for L.T.A. patients by time of onset from start of treatment. Neither the stage of the disease at start of L.T.A. treatment (Table VI) nor the age of the patient (Table VII) appear to affect the time of onset. The data suggest a mean period of incubation long in comparison with infective hepatitis, but do not of themselves entitle us to set clear-cut limits to it. More precise information is obtainable by recourse to corresponding data pertaining to patients treated by intensive methods, i.e. S.T.A. and PEN. Table VIII sets out data with respect to a six months' follow-up of such cases with corresponding data for transfusion jaundice (Tr.J).

Although the figures are small they consistently point to a mean period of incubation in the neighbourhood of 100 days. We have to bear in mind that they are not strictly comparable in so far as the date of exposure to the putative infective agent is defined within limits of 1 day for Tr.J cases, 9 days for PEN, and 20 days for S.T.A. The real incubation period for any case may fall short of the date of onset from start of treatment by these numbers. The incubation period of infective hepatitis is in the range 20-40 days. For what we may here collectively call serum hepatitis about $75 \%$ of cases occur 80 days or more after exposure and $50 \%$ occur within the range 80-120 days. Allowance for the margin of error in fixing the exact 
TABLE VIII

INCUBATION PeRIOD

\begin{tabular}{|c|c|c|c|c|c|c|c|c|c|c|c|c|c|c|c|}
\hline & \multicolumn{15}{|c|}{ DAYS FROM BEGINNING OF TREATMENT } \\
\hline & $0-19$ & $20-39$ & $40-59$ & $60-79$ & $80-99$ & $9100-119$ & \multicolumn{2}{|c|}{$120-139$} & $140-159$ & 9,160 & -179 & $9 \mid 180-199$ & \multicolumn{3}{|c|}{ Total } \\
\hline \multirow[t]{3}{*}{$\begin{array}{l}\text { S.T.A. } \\
\text { PEN } \\
\text { Tr.J }\end{array}$} & $\begin{array}{l}0 \\
0 \\
7 \cdot 7\end{array}$ & $\begin{array}{l}7 \cdot 1 \\
3 \cdot 7 \\
7 \cdot 7\end{array}$ & $\begin{array}{l}7 \cdot 1 \\
3 \cdot 7 \\
7 \cdot 7\end{array}$ & $\begin{array}{r}7 \cdot 1 \\
7 \cdot 4 \\
23 \cdot 1\end{array}$ & $\begin{array}{l}28 . \\
29 . \\
15 .\end{array}$ & $\begin{array}{l}14 \cdot 3 \\
29 \cdot 6 \\
23 \cdot 1\end{array}$ & $\begin{array}{r}28 \\
7 \\
6\end{array}$ & $\begin{array}{l}6 \\
4 \\
6\end{array}$ & $\begin{array}{r}7 \cdot 1 \\
11 \cdot 1 \\
7 \cdot 7\end{array}$ & $\begin{array}{l}0 \\
3 \\
0\end{array}$ & 7 & $\begin{array}{l}0 \\
3 \cdot 7 \\
0\end{array}$ & & $\begin{array}{l}00 \cdot 0 \\
00 \cdot 0 \\
00 \cdot 0\end{array}$ & \\
\hline & & \multicolumn{14}{|c|}{ Percentage Cases by Date of Onset } \\
\hline & & \multicolumn{2}{|c|}{$\begin{array}{l}\text { Under } \\
40 \text { days }\end{array}$} & \multicolumn{2}{|c|}{ 40-79 days } & \multicolumn{2}{|c|}{ 80-119 days } & \multicolumn{3}{|c|}{$120-159$ days } & \multicolumn{3}{|c|}{160 and over } & \multicolumn{2}{|c|}{ Total } \\
\hline \multicolumn{2}{|c|}{$\begin{array}{l}\text { S.T.A. } \\
\text { PEN } \\
\text { Tr.J } \\
\text { All }\end{array}$} & \multicolumn{2}{|c|}{$\begin{array}{r}7 \cdot 1 \\
3 \cdot 7 \\
15 \cdot 4 \\
7 \cdot 5\end{array}$} & \multicolumn{2}{|c|}{$\begin{array}{l}14 \cdot 2 \\
11 \cdot 1 \\
30 \cdot 8 \\
16 \cdot 7\end{array}$} & \multicolumn{2}{|l|}{$\begin{array}{l}42 \cdot 9 \\
59 \cdot 2 \\
38 \cdot 5 \\
50 \cdot 0\end{array}$} & \multicolumn{3}{|c|}{$\begin{array}{l}35 \cdot 7 \\
18 \cdot 5 \\
15 \cdot 4 \\
22 \cdot 2\end{array}$} & \multicolumn{3}{|c|}{$\begin{array}{l}0 \\
7 \cdot 4 \\
0 \\
3 \cdot 7\end{array}$} & \multicolumn{2}{|c|}{$\begin{array}{l}100 \cdot 0 \\
100 \cdot 0 \\
100 \cdot 0 \\
100 \cdot 0\end{array}$} \\
\hline
\end{tabular}

date of exposure does not materially distort these estimates. The contrast is all the more remarkable if we pay regard to the two modes of transmission. If infective and serum hepatitis are attributable to the same virus, there is prima facie reason to expect that the incubation period of the former would be longer, since the infective agent has to penetrate the site of the infection before it can establish itself elsewhere.

\section{Nature of the Icterogenic Agent of Serum Hepatitis}

The assumption that a venereal disease clinic constitutes a population isolate sui generis in virtue of procedure favourable to the spread of a putative infective agent of jaundice implies the existence within such a population isolate of a high incidence of any communicable disease which can be transmitted through blood as a medium. It is therefore pertinent to ask what was the incidence of known communicable, more especially virus, diseases in the syphilitic population, when the incidence of jaundice putatively attributable to a syringe-spread infection was at its peak level in the neighbourhood of $45 \%$. The ensuing table, which shows actual numbers of cases among Army syphilitics-U.K. 1943-44-supplies a sufficient answer and is particularly suggestive in so far as it lists diseases, e.g. rubella, which are certainly as common as infective hepatitis in the Army population. Total

population of Jaundice Rubella Chicken- lar syphilipox fever

Glandu-

Pneutics

$673 \quad 2$

$\begin{array}{ll}1 & 1 \\ 0 & 0 \\ 1 & 1\end{array}$

Herpes facialis

Herpes monia zoster (all forms) 
When we have to decide whether two clinical conditions are attributable to one and the same agent, we do well to remember that a single clear-cut difference overrides the value of any number of striking similarities. The collective weight of evidence set forth above therefore tells heavily against the view that the virus of infective hepatitis is responsible for serum (including so-called post-arsphenamine) jaundice. If so, we are faced with a nexus of new problems involving not merely the identification of the icterogenic agent itself but also its method of propagation.

That the icterogenic agent is a virus receives strong support from several circumstances: its heat lability, its delayed action, and the minute quantities of blood which can convey it. These circumstances, in themselves highly suggestive, are not wholly conclusive. They are indeed consistent with the assumption that the icterogenic agent is a heat-labile by-product of the normal metabolism of certain individuals capable of slow pathogenic action in other individuals. The relevant distinction implicit in the usual connotation of the term virus is whether or not the agent is capable of growth. In practice, this signifies that we can dilute it indefinitely and recover from a minute fraction of the original source a quantity equivalent to what was originally present in the source itself. In the absence of methods of assay in vitro the only way of reaching a decisive conclusion about this is to test whether it retains its efficacy after transmission through a chain of test subjects successively inoculated with minimal quantities of sera or whole blood. By recourse to this method, Paul et al. (1945) have obtained highly suggestive indications in favour of the view that the icterogenic agent of serum hepatitis is amenable to indefinite dilution.

It is clearly important to seek such indications preferably by recourse to a suitable test animal if such can be found, alternatively by experiments on human volunteers willing to submit to a procedure with attendant risks that are by no means trivial. Meanwhile, it is not unprofitable to examine the implications of the assumption that the agent of delayed serum hepatitis is in fact a virus. Within the framework of this provisional assumption we have to meet the challenge of three conclusions suggested by our enquiry:

(i) there exists a small but not inconsiderable group of persons who are carriers of the icterogenic agent;

(ii) a high proportion of persons-perhaps as many as $50 \%$-are resistant to its effects when introduced into the circulation;

(iii) its introduction into the circulation of individuals does not appear to confer immunity to subsequent inoculation.

The last of these three conclusions is least firmly established and further examination of its consequences vis $\grave{a}$ vis the foregoing assumption will make clear the importance of establishing it firmly or discrediting its validity. The assertion that the virus of infective hepatitis is not the icterogenic agent of delayed serum hepatitis implies that infective hepatitis as a disease endemic or epidemic in a normal population is a singular clinical entity. This assumption is not beyond 
dispute, but its provisional acceptance is worth while, if only because the inescapable result of accepting it emphasizes the need for further assurance. If we do accept it, we are driven to the conclusion that delayed serum hepatitis is a disease of which the only known vector is the physician and the only known organ by which the vector can transmit the infective agent is the syringe.

Within the compass of the preceding assumptions, which admittedly call for more rigorous validification, we are thus led to ask by what means the putative virus can persist endemic within a population not exposed to artificial methods of transmission. It may be that further research will reveal possibilities other than such as existing information suggests. The possibility that viruses may arise de novo in the living body is repugnant to current teaching; and if it is not necessarily inconceivable in the light of the most recent research on their nature it would assuredly be over-bold to reopen the discussion of spontaneous generation without exploring an alternative which comes within the province of available experience and has more to commend it on other grounds. Among plants we have long been familiar with viruses which maintain their existence within a population by transmission through successive generations of individuals, each affected parent being a vector for its own offspring. The infective agents of the so-called mosaic diseases have indeed three characteristics which are at least suggestive in this context: (a) they require no vector nor any such external medium of propagation as droplet or faecal infection imply; $(b)$ they confer no immunity by their presence; $(c)$ the effects of their presence, though manifest, may be entirely innocuous, as is true of the mosaic virus of variegated tulips.

To be sure, propagation of this sort commonly goes with vegetative reproduction of the plant host; but the viruses of bean mosaic and lettuce mosaic are conveyed by the ovule. Hence there is nothing to exclude the possibility that human transmission could be accomplished through the medium of sexual generation via either one or both of the gametes, by transplacental spread to the foetus or by lactation. In this context it would be premature to advocate any such a hypothesis of parental transmission without further examination of issues which remain dubious and of alternatives which may suggest themselves in the light of new data. Meanwhile such speculations are not fruitless, if they focus attention more sharply on the needs to elucidate three issues: $(a)$ whether the icterogenic agent of serum hepatitis is in fact a virus; $(b)$ whether cases of an identical nature do in fact occur in the absence of artificial means of propagating a blood-borne infection; $(c)$ what fraction of a normal population are carriers of an icterogenic agent.

\section{Practical implications}

Data presented earlier in this communication suggest not only theoretical issues for further research but positive guidance for the practice of preventive medicine. It is convenient to consider these separately with respect to jaundice associated with syphilis therapy and with blood transfusion.

(a) Evidence here presented confirms the view that the majority of cases of 
jaundice associated with syphilis therapy are the result of an icterogenic agent transferred from patient to patient through the medium of imperfectly sterilized syringes. When sterilization procedures are inadequate in venereal disease clinics a very high proportion ( $50 \%$ ) of syphilis patients may develop jaundice as a result of their peculiar liability to this condition. Sterilization by boiling reduces the incidence of jaundice to trivial proportions. In view of the high incidence of jaundice associated with one series of penicillin-treated cases, it is apparent that a high standard of sterilization procedure should be maintained irrespective of the therapeutic agent employed. Indeed, the chemical nature of the therapeutic agents in the doses commonly used seems to be of negligible importance.

(b) In view of the widespread use of blood transfusion as a therapeutic measure, it is important to evaluate the magnitude of the risk of jaundice following transfusion. Evidence presented in Section 5 yields a clear-cut answer. When blood comes from single donors, transfusion carries a negligible risk of subsequent delayed jaundice. On the other hand, use of plasma from large pools of blood obtained from many donors makes the risk of delayed jaundice by no means negligible (5\% in this series).

These findings are consonant with the experience of Loutit and Maunsell (1945) who found that no cases of jaundice occurred among subjects inoculated with plasma obtained from 96 single donors. It thus seems clear that the use of blood or blood products obtained from large pools should be abandoned in civilian medical practice. On the other hand stable blood products may be needed on a vast scale under conditions of active warfare, when the risk of jaundice may be of small account by comparison with the advantages of mass production from large pools of blood. To what extent large-scale production from pools of a few donors only is then practicable is an issue to be decided with due regard to considerations relevant to methods of manufacture.

\section{Summary}

1. Of syphilis patients starting long-term arsenic treatment in military V.D. centres in U.K. during the first half of 1943, approximately half developed jaundice during treatment. Following introduction of improved sterilization procedures, incidence of jaundice underwent a spectacular decline, until it was about $5 \%$ in the second half of 1944. This confirms the view that the majority of cases of jaundice associated with treatment of syphilis are due to a syringe-spread heatlabile icterogenic agent.

2. Different arsenicals are associated with similar incidence of jaundice during treatment. During the treatment when incidence of jaundice was sharply declining, incidence of arsenical dermatitis remained steady. Under propitious circumstances, penicillin treatment is also attended by high incidence of jaundice. In doses commonly employed; arsenicals therefore seem to exert little or no influence on liability to jaundice. 
3. On the other hand, the syphilitic process seems to increase susceptibility to jaund ce, susceptibility being greatest during the very early stages of syphilis.

4. Transfusion with blood obtained from single donors carries a negligible risk of subsequent delayed jaundice. Transfusion of blood or blood products obtained from large pools carries a significantly higher risk of subsequent jaundice (about $5 \%$ in this series).

5. Although subject to great variation the most common incubation period of serum hepatitis, both among syphilitic patients and Army patients who receive blood transfusion, is in the region of 100 days. This is much more protracted than the incubation period of infective hepatitis (21-40 days).

6. During the period of high incidence of jaundice, the incidence of other communicable diseases in the syphilitic population was negligible. Whereas infective hepatitis is relatively more common among the youngest Army age groups, age has little or no influence on liability to jaundice among syphilitics. These findings converge with other evidence to the conclusion that the virus of infective hepatitis is not the icterogenic agent responsible for jaundice among syphilitics.

7. The theoretical implications of the view that serum hepatitis is due to a virus which is not that of infective hepatitis are challenging in so far as they prompt the question: By what means does the virus persist endemic in the population? A possible interpretation is the subject of discussion in Section 7.

8. Two important practical implications emerge from this study:

(a) because syphilitics are unduly liable to jaundice, a high standard of sterility must be maintained during their treatment, irrespective of what therapeutic agents are employed;

(b) the use of blood or blood products obtained from large pools should be abandoned in civilian medical practice, though their use may still be justifiable under the special conditions of active warfare.*

\section{REFERENCES}

Beattie, J., and Marshall, J. (1944). Brit. med. J., 1, 547.

Beeson, P. B. (1943). J. Amer. med. Ass., 121, 1,332.

Circular Letter No. 95 of the Surgeon General (1942). Ibid., 120, 51.

Havens, W. P., Paul, J. R., van Rooyen, C. E., Ward, R., Drill, V. A., and Allison, Nancy H. (1945). Lancet, 1, 202.

Hogben, L., and Johnstone, M. M. (1946). In the press.

Loutit, J. F., and Maunsell, K. (1945). Brit. med. J., 2, 759.

MacCallum, F. O. (1943). Brit. J. Vener. Dis., 19, 63.

McKinlay, P. L., and Truelove, S. C. (1946). Brit. J. soc. Med., 1, 33.

Ministry of Health Memorandum (1943). Lancet, 1, 83.

Morgan, H. V., and Williamson, D. A. J. (1943). Brit. med. J., 1, 750.

Paul, J. R., Havens, W. P., Sabin, A. B., and Philip, C. B. (1945). J. Amer. med. Ass., $128,911$.

Pickles, W. N. (1939). Epidemiology in Country Practice. London.

Salaman, M. H., King, A. J., Williams, D. I., and Nicol, C. S. (1944). Lancet, $2,7$.

Steiner, R. E. (1944). Brit. med. J., 1, 110.

* Since this article went to press, the British Medical Journal (September 21st, 1946, p. 409) has published one by Spurling, Shone, and Vaughan, who have independently established by more extensive observations the conclusion that blood transfusion with pooled serum or plasma is associated with a much higher risk of serum hepatitis than is transfusion with whole blood from individual donors. 